\title{
Effects of oils, lotions, hand sanitizers, and mehendi on fingerprints captured through digital fingerprint scanner
}

\author{
Vinita Kumari ${ }^{1 *}$, Mukesh Kumar Thakar ${ }^{1}$, Biswajit Mondal ${ }^{2}$ and Surender Kumar Pal ${ }^{3}$
}

\begin{abstract}
Background: In this modern era, advancement in technology is seen in every aspect of our life making it comparatively much easier. Likewise, in the field of fingerprinting, the digital scanners have replaced conventional methods of taking fingerprints, as it is accurate and less time-consuming. In daily life, people often apply oils, lotions, hand sanitizers, and occasionally mehendi on their hands. These cosmetic and daily use products affect the digital recording of fingerprints, thus making it difficult for forensic experts to identify the real offender in many cases. The purpose of the study was to check the effect of oils, lotions, hand sanitizers, and mehendi on the fingerprint pattern.

Results: The present study was undertaken by taking 2700 fingerprints from 30 individuals. These fingerprints were recorded with the help of the SecuGen Hamster IV fingerprint scanner under controlled environmental conditions. The examination and comparison of fingerprint patterns were done on the basis of visibility (clarity and intensity). The presence of cosmetic and daily use products affected the visibility of digitally captured fingerprints. Different products caused different effects based on their properties. Synthetic mehendi, alcohol-based hand sanitizer, greasy lotion, and viscous oil caused significant differences in the fingerprint images by degrading the fingerprint quality. The non-greasy lotion and non-alcohol-based hand sanitizer showed less effect, whereas non-viscous oil and natural mehendi caused a minimal effect on the quality of fingerprint images.

Conclusion: The application of cosmetic and daily use products added an additional layer on the fingers which is not present naturally. The additional layer caused alterations in the fingerprint pattern of an individual. So, digital fingerprints should be collected after proper washing of hands.
\end{abstract}

Keywords: Fingerprints, Digital fingerprint scanner, Oils, Lotions, Hand sanitizer, Mehendi

\section{Background}

Every human being has unique features on the palmer surfaces in the form of fingerprints, which remain unaltered throughout life and acts as an individual's visiting card. A fingerprint is an impression of the friction ridges present on the distal, middle, and proximal phalange regions of the fingers (Grieve 2001; Maceo 2009). These fingerprints are formed during the second trimester of fetal life. Fingerprint impressions are encountered at the

\footnotetext{
* Correspondence: vinitakumari3494@gmail.com

${ }^{1}$ Department of Forensic Science, Punjabi University, Patiala, Punjab, India Full list of author information is available at the end of the article
}

scene of crime, and these are formed due to the body's natural oils and sweat secretions. Fingerprints are used in individual's background check, biometric security, and different types of criminal cases. Even identical twins have different fingerprints, so these are considered to be one of the most reliable physical evidence in linking the suspect and victim (Champod et al. 2016; Wayase and Chaulang 2018; Win et al. 2020).

Earlier fingerprints were recorded by using black ink, but nowadays, different fingerprint scanners are used to record fingerprints without using any type of ink. In this, fingerprints are taken digitally, and identification of an 
individual is done easily by their unique fingerprint features like frictional ridge characteristics, minutiae, and sweat pores. This is an inkless, non-messy, simple, cost-effective, and faster processing technique. High-resolution images are captured by the fingerprint scanners, and detailed examination is performed by magnifying the fingerprint image which is not possible in traditional methods. The digital method provides quicker and accurate results, and we can compare a large number of fingerprint data simultaneously (Traditional vs. digital ink fingerprinting 2015; Biometric fingerprint scanner 2008; Fingerprint scanners: what they are and why they are gaining in popularity 2019). The fingerprint data is electronically transmitted to these Automated Fingerprint Identification System (AFIS) for authentication, verification, and generating a database of the perpetrators (Automated Fingerprint Identification System 2014). Similarly, in India, the Unique Identification Authority of India (UIDAI) Adhaar card contains the biometric database including fingerprints of every citizen which can be used to identify the individual (Unique Identification Authority of India, Government of India 2016; Vatsa et al. 2010).

With the modernization of the procedure to record fingerprints, the offenders try to manipulate by applying some cosmetic and daily use products (oils, lotions, hand sanitizers, and mehendi) on their hands. These products are used by most people in their day-to-day life. Oil is used for moisturizing the epidermal layer of the skin. Lotion is used to keep the skin soft, hydrated, and moisturized (Merkel et al. 2011; Arndt 1998). Hand sanitizer is used to kill the infectious agents (fungi, bacteria, and virus) present on the hands (Chadwick et al. 2017; Olsen et al. 2015). In India, mehendi is especially used by women to color the epidermal layer of the palmer and planter surfaces during some rituals and ceremonies. Mehendi is a dye made from the leaves of the plant Lawsonia inermis. The dye present in the leaves gets stained on the skin surface resulting in dark red cherry coloration of the skin (What is mehendi? 2002; Butalia et al. 2017). The presence of these products can affect the visibility (clarity and intensity) of the image as the device records images of the raised portion of the frictional ridges

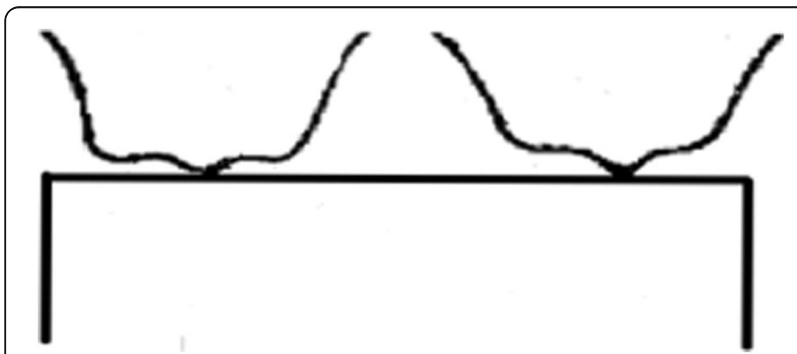

Fig. 1 An illustrative diagram of the surface discontinuities on the fingerprint ridge of a dry finger when nothing is applied over it

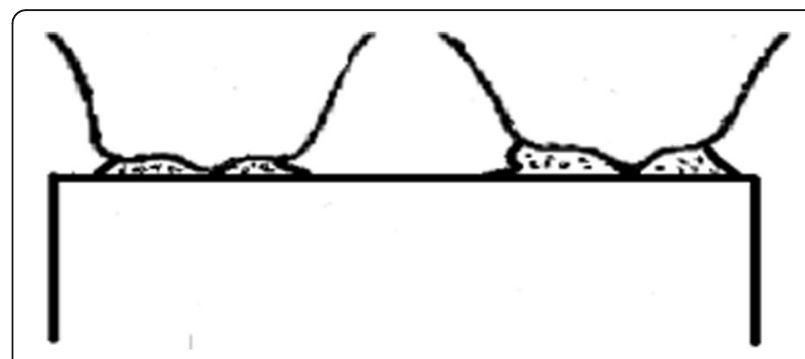

Fig. 2 An illustrative diagram of the surface after applying a liquid composition on the fingerprint surface

of the palmer surface which makes direct contact with the glass surface of the scanner. These raised portions of frictional ridges are used to identify the real offender. If there is any kind of obstruction between the frictional ridge skin and the glass surface of the fingerprint recording device, a poor quality fingerprint image will be recorded (Turvey 2017; Keagy et al. 1998). Due to this obstruction, it becomes difficult to identify frictional ridge characteristics resulting in change in the identity of a person. The changes that occur on applying these cosmetic products on the finger ridges are shown in Figs. 1 and 2.

The study focuses on the cause, effect, and detection of fingerprint patterns of an individual by applying oils, lotions, hand sanitizers, and mehendi.

\section{Methods}

\section{General procedure}

The study was conducted at the Department of Forensic Science, Punjabi University, Patiala, India. Fingerprint samples of 30 subjects were taken by applying 8 different cosmetic and daily use products (oils, lotions, hand sanitizers, and mehendi) including viscous (Mustard oil), non-viscous (Parachute advanced jasmine non-sticky oil), greasy (Nivea body lotion express hydration 48h), non-greasy (VLCC almond honey deep nourishing and skin brightening body lotion), alcohol-based (Lifebuoy immunity-boosting hand sanitizer), non-alcohol-based (Kudos hand sanitizer), synthetic (Kaveri cone mehendi), and natural (Neha mehendi). A total of 2700 fingerprints were collected under controlled environmental conditions. Subjects were asked to wash and dry their hands to remove any kind of foreign particles before the application of each product.

\section{Fingerprint recording}

The sgdx software of SecuGen hamster IV fingerprint scanner (File version-4.4.3.0 and Product version-1.1.0.0) was used for sample collection of fingerprints. Subjects were requested to press their fingers against the fingerprint scanner for collecting the desired fingerprint samples. Firstly fingerprints were collected without application 
Table 1 Standard categories used for differentiation of fingerprints after applying products (Sears et al. 2012; Almog et al. 2014)

\begin{tabular}{|c|c|c|c|}
\hline S. no. & Category of print & Features of fingerprints & $\begin{array}{l}\text { Visibility score } \\
\text { value }\end{array}$ \\
\hline 1. & $\begin{array}{l}\text { Very strong development (without application of } \\
\text { product) control sample }\end{array}$ & $\begin{array}{l}\text { Identifiable fingerprint pattern, clear ridge details, minutiae, } \\
\text { and sweat pores were clearly visible, no merging of the ridges, } \\
\text { prominent appearance of the ridges, and fingerprint classification }\end{array}$ & $81-100$ \\
\hline 2. & Strong development (with application of product) & $\begin{array}{l}\text { Identifiable fingerprint pattern, clear ridge details, partially visible } \\
\text { minutiae and sweat pores, slightly broad margins of the ridges } \\
\text { and few or no clump-like formation, and less prominent merging } \\
\text { of ridges at some points }\end{array}$ & $61-80$ \\
\hline 3. & Medium development (with application of product) & $\begin{array}{l}\text { Fingerprint pattern can or cannot be identified, broad margins } \\
\text { and merging of the ridges, non-identifiable ridge details, less } \\
\text { chances of appearance of sweat pores and minutiae, and less } \\
\text { prominent appearance of the ridges }\end{array}$ & $41-60$ \\
\hline 4. & Limited development (with application of product) & $\begin{array}{l}\text { Partially visible fingerprint pattern, ridge details not clear, visible } \\
\text { sweat pores, and no merging of the ridges }\end{array}$ & $21-40$ \\
\hline 5. & Weak development (with application of product) & $\begin{array}{l}\text { Fingerprint pattern can or cannot be identified, no visible ridge } \\
\text { characteristics, and visibility of sweat pores with less appearance } \\
\text { of the ridges }\end{array}$ & $0-20$ \\
\hline
\end{tabular}

of any cosmetic and daily use products which were taken as controls followed by the application of these products on the palmer surface. Two drops of each product were poured on the palmer surface, and subjects were asked to rub their hands gently so that the product could be applied properly. The product was left for $10 \mathrm{~min}$ for absorption by the skin surface before taking fingerprints. This step was repeated for each product except mehendi.
Synthetic and natural mehendi were applied in the form or design of plus sign on the bulb of the first distal phalangeal region of the fingers to check the effect of mehendi on the specified applied area. Firstly, synthetic mehendi was applied. After application, mehendi was left on hands for $10 \mathrm{~min}$, so that dye present in the mehendi can get absorbed by the skin surface. Afterwards, mehendi was removed by washing the hands with tap water and drying

\begin{tabular}{|c|c|c|c|}
\hline $\begin{array}{l}\text { a. Mustard oil } \\
\text { (Viscous) }\end{array}$ & $\begin{array}{l}\text { c. Nivea lotion } \\
\text { (Greasy) }\end{array}$ & $\begin{array}{c}\text { e. Lifebuoy hand } \\
\text { sanitizer } \\
\text { (Alcohol based) }\end{array}$ & $\begin{array}{l}\text { gen } \\
\text { g. Kaveri mehendi } \\
\text { (Synthetic) }\end{array}$ \\
\hline 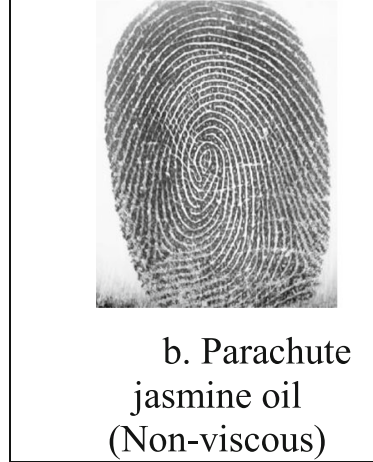 & $\begin{array}{l}\text { d.VLCC lotion } \\
\text { (Non-greasy) }\end{array}$ & $\begin{array}{l}\text { (Non-alcohol based) } \\
\text { sanitizer } \\
\text { (Nondos hand } \\
\text { (Non) }\end{array}$ & h. Neha mehendi \\
\hline $\begin{array}{l}\text { Fig. } 3 \text { Fingerprint images reco } \\
\text { viscous). c Nivea lotion (greasy) } \\
\text { g Kaveri mehendi (synthetic). } \mathbf{h}\end{array}$ & $\begin{array}{l}\text { cation of cosmetic ar } \\
\text { (non-greasy). e Lifeb } \\
\text { i (natural) }\end{array}$ & $\begin{array}{l}\text { products. a Mustard oil (vis } \\
\text { anitizer (alcohol-based). } \mathbf{f} \text { Ku }\end{array}$ & $\begin{array}{l}\text { chute jasmine oil (non- } \\
\text { nitizer (non-alcohol-based) }\end{array}$ \\
\hline
\end{tabular}


Table 2 Comparison showing effects of products on fingerprints

\begin{tabular}{|c|c|c|}
\hline no. & Cosmetic and daily use products & Effects of cosmetic and daily use products on fingerprints \\
\hline 1. & Mustard oil (viscous) & $\begin{array}{l}\text { Identifiable fingerprint pattern, no clear ridge details and visibility of sweat pores, merging of the ridges, } \\
\text { very dark appearance of the fingerprint, broadened up margins of the ridges, and medium development } \\
\text { of fingerprints }\end{array}$ \\
\hline 2. & $\begin{array}{l}\text { Parachute jasmine oil } \\
\text { (non-viscous) }\end{array}$ & $\begin{array}{l}\text { Identifiable fingerprint pattern, clear ridge details, no merging of the ridges and visibility of sweat pores, dark } \\
\text { appearance and strong development of fingerprints, and no clump-like structure formation on the ridges }\end{array}$ \\
\hline 3. & Nivea lotion (greasy) & $\begin{array}{l}\text { Identifiable fingerprint pattern, partially clear ridge details, no visibility of sweat pores, very dark appearance } \\
\text { of the fingerprint, clump-like structure formation on the ridges, and medium development of fingerprints }\end{array}$ \\
\hline 4. & VLCC lotion (non-greasy) & $\begin{array}{l}\text { Identifiable fingerprint pattern, clear ridge details, no merging of the ridges and visibility of sweat pores, } \\
\text { light appearance of the fingerprint, few clump-like structure formation on the ridges, and strong } \\
\text { development of fingerprints }\end{array}$ \\
\hline 5. & $\begin{array}{l}\text { Lifebuoy hand sanitizer } \\
\text { (alcohol-based) }\end{array}$ & $\begin{array}{l}\text { Fingerprint pattern can or cannot be identified, ridge details not clear, visibility of sweat pores, no merging } \\
\text { of the ridges and clump-like structure formation on the ridges, very light appearance of the fingerprint, } \\
\text { partially visible fingerprint, and weak development of fingerprints }\end{array}$ \\
\hline 6. & $\begin{array}{l}\text { Kudos hand sanitizer } \\
\text { (non-alcohol based) }\end{array}$ & $\begin{array}{l}\text { Identifiable fingerprint pattern, clear ridge details, no merging of the ridges, visibility of sweat pores, light } \\
\text { appearance of the fingerprint, no clump-like structure formation on the ridges, and medium development } \\
\text { of fingerprints }\end{array}$ \\
\hline 7. & $\begin{array}{l}\text { Kaveri cone mehendi } \\
\text { (synthetic) }\end{array}$ & $\begin{array}{l}\text { Fingerprint pattern can or cannot be identified, partially visible fingerprint, ridge details not clear, no } \\
\text { merging of the ridges and clump-like structure formation on the ridges, visibility of sweat pores, very light } \\
\text { appearance of the fingerprints, and limited development of fingerprints }\end{array}$ \\
\hline 8. & Neha mehendi (natural) & $\begin{array}{l}\text { Identifiable fingerprint pattern, clear ridge details, no merging of the ridges and visibility of sweat pores, } \\
\text { no clump-like structure formation on the ridges, dark appearance of the fingerprints, and strong } \\
\text { development of fingerprints }\end{array}$ \\
\hline
\end{tabular}

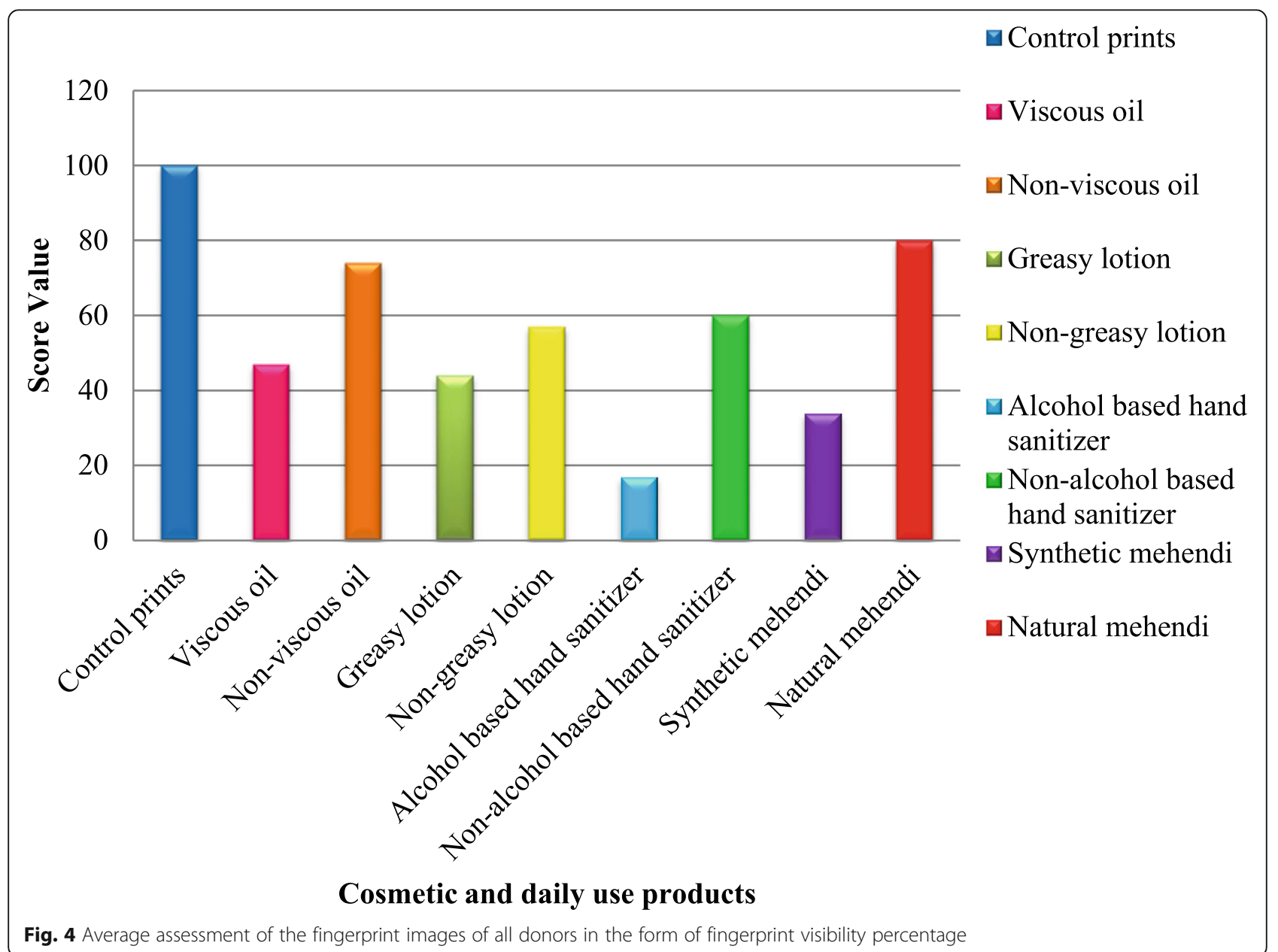




\begin{tabular}{|l|l|l|l|l|l|}
\hline $\begin{array}{l}\text { Natural } \\
\text { mehendi }\end{array}$ & \multicolumn{2}{l}{$\begin{array}{l}\text { Non-alcohol } \\
\text { based hand } \\
\text { sanitizer }\end{array}$} & $\begin{array}{l}\text { Viscous } \\
\text { oil }\end{array}$ & \multicolumn{2}{l|}{$\begin{array}{l}\text { Synthetic } \\
\text { mehendi }\end{array}$} \\
\hline & & & & & \\
\hline & $\begin{array}{l}\text { Non-viscous } \\
\text { oil }\end{array}$ & $\begin{array}{l}\text { Non-greasy } \\
\text { lotion }\end{array}$ & $\begin{array}{l}\text { Greasy } \\
\text { lotion }\end{array}$ & $\begin{array}{l}\text { Alcohol } \\
\text { based hand } \\
\text { sanitizer }\end{array}$ \\
\hline
\end{tabular}

Fig. 5 Visibility percentage of the fingerprint patterns

hands with a paper towel, and then fingerprints were recorded. After few days when the applied synthetic mehendi got faded, natural mehendi was applied on the bulb of the first distal phalangeal region in the same manner, and fingerprints were taken. The output of scanned fingerprints was saved in a higher resolution of .bmb format.

\section{Fingerprint analysis}

In order to study the effect of the products on the surface of frictional ridges of fingers, all the fingerprint patterns were examined and compared with the controls on the basis of visibility of fingerprint pattern (clarity and intensity) given in Table 1 . The category of control was considered to be very strong as it contained all the features like classification of fingerprint pattern with clear ridge details, minutiae, and sweat pores, without merging of the ridges. The control fingerprints were compared with the fingerprints recorded after the application of the product. The products were considered as class (oils, lotions, hand sanitizers, and mehendi) and further divided into two subclasses on the basis of their properties. The features which were common in most of the individuals were taken into consideration, and a range of score value was assigned to each category on the basis variation with the control sample. The factors causing natural variation (like absorption of the product by the skin, sweat secretion) were excluded in order to minimize the chances of errors. Five categories (very strong, strong, medium, limited, and weak development) of fingerprints were taken to check the differences between the fingerprints after the application of the products. The description was given to each category of print shown in Table 1 . The differences between fingerprints recorded with and without the application of the products were noted. Qualitative analysis was done on the basis of visibility and quality of the fingerprints. Intra and inter-comparisons between the classes and their subclasses were done. Written consent was obtained from all the subjects, and ethical clearance was taken from the institute.

\section{Results}

The effects of the use of oils, lotions, hand sanitizer, and mehendi were seen on the frictional ridge of the distal phalangeal region. All the subclasses of every class were analyzed, and the observations were made. The difference in clarity and intensity of fingerprints like broadening with merging of ridges, clump-like structure formation, visibility of only few or no frictional ridges, and faint pattern in some or the whole areas of fingerprint was seen in fingerprints with and without application of products (controls) were shown in Fig. 3 . The prominent broadening with merging of ridges in fingerprint pattern was found in viscous oil (Fig. 3a) and less prominent in non-viscous oil (Fig. 3b). The prominent clump-like structure in the fingerprint pattern was seen in greasy substance (Fig. 3c) and less prominent in nongreasy lotions (Fig. 3d). A few or no frictional ridges in the fingerprint pattern were found in alcohol-based hand sanitizer (Fig. 3e) which was not commonly encountered in case of non-alcohol-based hand sanitizer (Fig. 3f). Synthetic mehendi leads to poor visibility of the fingerprint on the applied area (Fig. 3g) whereas no such prominent effect was seen in the fingerprints recorded with natural mehendi (Fig. 3h).

The features showing the differences in fingerprints observed in all the subclasses after the application of products were elaborated in Table 2. Intra and intercomparisons between fingerprints are shown in Table 2.

On the basis of the results, a bar diagram showing the visibility percentage of the fingerprints including qualitative analysis based on clarity and intensity of fingerprints was shown in Fig. 4. This showed the intra and intercomparison between controls and all classes and subclasses of the products. The score value of the product showing the maximum effect on the fingerprints was taken into consideration. Fingerprints showing low score 
value were not considered as the effect of products was minimal due to natural variation. The maximum score value was given to the control samples as all the features were seen clearly which were easily classifiable.

The visibility percentage of various products on the fingerprint pattern has been shown in descending order in Fig. 5.

\section{Discussion}

In our study, some products have more effect, some have less effect on the visibility, some products were quickly absorbed on the skin surface while others took longer time and some added an additional layer over the surface of frictional ridge skin. Viscous oil, greasy lotion, alcohol-based hand sanitizer, and synthetic mehendi produced a high effect on the fingerprint quality by overpowering the natural ridge characteristics. Nongreasy lotion and non-alcohol-based hand sanitizer showed a medium effect whereas non-viscous oil and natural mehendi caused a low effect on the fingerprint pattern.

The present study revealed that the viscous oil reduced the fingerprint quality which leads to medium development of fingerprints whereas the non-viscous oil had a strong development of fingerprints. This is due to the variation in density of viscous and non-viscous oils, as the absorption rate of viscous oil on the skin is very low. Turvey mentioned that the mixture comprising of viscous and non-viscous oil (60\% beeswax, 30\% squalane, $9 \%$ jojoba oil, and $1 \%$ tea tree oil) improves the fingerprint quality (Turvey 2017). Arndt mentioned that nonviscous oil improves the fingerprint quality (Arndt 1998).

In the present study, the medium development and reduced fingerprint quality were observed in greasy lotion as it was not completely absorbed by the skin and got filled up in the furrows. Non-greasy lotion showed less effect on the fingerprint quality as compared to greasy lotion and leads to the medium development of fingerprint. Our study is in agreement with Arndt who reported that greasy substances lead to reduced fingerprint quality (Arndt 1998).

Our study showed that the presence of both alcohol and non-alcohol-based hand sanitizer on the palmer surface reduced the fingerprint quality when fingerprints were recorded digitally. Alcohol-based hand sanitizer produces weak development of fingerprints showing a few or no frictional ridge. Non-alcohol-based hand sanitizer produced medium development of fingerprint pattern. Both alcohol and non-alcohol-based hand sanitizers swiped off the sebum, lipids, dirt, and grease traces present on the surface of the frictional ridge skin, and due to this, the scanner could not record the fingerprints properly. The results of the present study contradict with Chadwick et al. who took fingerprints by using traditional methods and reported that non-alcohol-based hand sanitizer improves the fingerprint quality and alcohol-based hand sanitizer has no effect on fingerprint quality. Chadwick et al. reported that non-alcoholic hand sanitizers lead to an observable increase in the fingerprint quality when developed by using amino acid reagents. These changes occurred due to the difference in fingerprint recording methods (Chadwick et al. 2017).

In this study, the fingerprints recorded by applying synthetic mehendi produced limited development of fingerprints with poor quality of image having less number of desired fingerprint features as it added an additional layer on the ridges. The distance between ridges is either expanded or contracted in few regions which finally changes the distance between the ridges. Synthetic mehendi has a chemical known as paraphenylenediamine, and if the mehendi is kept on the fingers for a longer time, then the print will be fainter and hardly detected by the scanner. Natural mehendi does not contain any chemical, so no such prominent effect was observed on the fingerprint pattern. Our study is in concordance with the study of Butalia et al. who reported the same effect of mehendi on fingerprints recorded digitally (Butalia et al. 2017).

\section{Conclusion}

The presence of oil, lotion, hand sanitizer, and mehendi on the palmer surface affects the fingerprint quality. The accurate identification of an individual could be ascertained, if the fingerprint pattern shows clear ridge characteristics, minutiae, and pore details. If there is any kind of distortion in the frictional ridges, it will cause errors on the digital scanner. The errors can be seen in the form of broadening with merging of the ridges, formation of clump-like structure, visibility of only a few or no frictional ridges, and faint pattern in some or the whole areas of the fingerprint where the product was applied. The products add an additional layer in the fingerprint pattern which is not present naturally. These errors should be rectified before recording any fingerprint digitally as they can mislead the identification, so fingerprints should be taken after proper washing of hands. In any case, if there is less moisture on the palmer surface of the individual and the scanner is not able to detect the fingerprint pattern clearly, then few drops of normal tap water or distilled water should be used to moisten the palmer surface because water does not add any impurity or additional layer. Any defect in fingerprint development or any mistake in the procedure will most probably result in losing the assailant or letting him free rather than putting an innocent in prison. 


\section{Abbreviations}

AFIS: Automated Fingerprint Identification System; UIDAl: Unique Identification Authority of India

\section{Acknowledgements}

Not applicable

\section{Authors' contributions}

VK was responsible for the sample collection, analysis, interpretation of the data, and writing of research. MKT contributed to the idea of the research, study design, and supervision of the work and approved the version to be published. VK and BM conducted the retrieval of the literature and statistical analysis. SKP contributed in manuscript writing and revised it critically for important intellectual contents. All the authors have read and approved the final manuscript.

\section{Funding}

No funding was received for this research study.

\section{Availability of data and materials}

Please contact the authors for data requests.

\section{Declarations}

Ethics approval and consent to participate

This study was undertaken by me as a dissertation study while doing Postgraduation in Forensic Science.

The study was approved by the institutional ethics committee, Punjabi University, Patiala vide Reg. No. IEC/01-2018/019 consisting of the chairman and member secretary. A certificate letter was issued for the study with their signatures. Written informed consent was obtained from all the participants participating in the study which was approved by the ethics committee.

\section{Consent for publication}

Not applicable

\section{Competing interests}

The authors declare that they have no competing interests.

\section{Author details}

'Department of Forensic Science, Punjabi University, Patiala, Punjab, India. ${ }^{2}$ Department of Forensic Science, Galgotias University, Greater Noida, UP, India. ${ }^{3}$ Biology \& Serology Division, Regional Forensic Science Laboratory, Northern Range, Dharamshala, Himachal Pradesh, India.

Received: 13 July 2020 Accepted: 14 April 2021

Published online: 14 May 2021

\section{References}

Almog J, Cantu AA, Champod C, Kent T (2014) Guidelines for the assessment of fingermark detection techniques international fingerprint research group. J Forensic Ident 64(2):174-200 Accessed 2 June 2020

Arndt DC (1998) Method and apparatus for enhancing live-scan fingerprint reader images. US Patent 5,737,071, 7 Apr 1998

Automated fingerprint identification system 2014. https://www.m2sys.com/a utomated-fingerprint-identification-system-afis/. Accessed 20 May 2020.

Biometric fingerprint scanner 2008. https://www.explainthatstuff.com/ fingerprintscanners.html. Accessed 10 Apr 2020

Butalia A, Ingali S, Kulkarni M (2017) Enhanced fuzzy feature match algorithm for mehendi fingerprints. Int J Future Rev Comput Sci Comm Eng 3(10):188-197

Chadwick S, Neskoski M, Spindler X, Lennard C, Roux C (2017) Effect of hand sanitizer on the performance of fingermarks detection techniques. Forensic Sci Int 273:153-160. https://doi.org/10.1016/j.forsciint.2017.02.018

Champod C, Lennard C, Margot P, Stoilovic M (2016) Fingerprints and other ridge skin impressions, 2nd edn. CRC Press, New York

Fingerprint scanners: what they are and why they are gaining in popularity 2019. https://www.lifewire.com/understanding-finger-scanners-4150464. Accessed 4 May 2020

Grieve DL (2001) Scientific working group on friction ridge analysis, study and technology. J Forensic Ident 51(3):222-299
Keagy JN, Pinkhasik N, Muzel A (1998) Apparatus and method for electronically acquiring fingerprint images with low cost removable platen and separate imaging device. US Patent 5,732,148, 24 March 1998

Maceo AV (2009) Qualitative assessment of skin deformation: a pilot study. J Forensic Ident 59(4):390-440

Merkel R, Dittmann J, Vielhauer C (2011) How contact pressure, contact time, smearing and oil/skin lotion influence the aging of latent fingerprint traces: first results for the binary pixel feature using a CWL sensor. In: Paper presented at the International Workshop on Information Forensics and Security, Iguacu Falls, Brazil, 29 Nov- 2 Dec 2011. https://doi.org/10.1109/ WIFS.2011.6123153

Olsen MA, Dusio M, Busch C (2015) Fingerprint skin moisture impact on biometric performance. In: Paper presented at the 3rd International Workshop on Biometrics and Forensics. Gjovik, Norway, 3-4 March 2015

Sears VG, Bleay SM, Bandey HL, Bowman VJ (2012) A methodology for fingermark research. Sci Justice 52(3):145-160. https://doi.org/10.1016/j.scijus.2011.10.006

Traditional vs. digital ink fingerprinting 2015. https://www.bartonassociates.com/ blog/digital-vs-traditional-ink-fingerprinting. Accessed 3 Apr 2020.

Turvey J (2017) Preparation for enhanced fingerprint image formation on a transparent surface of a live-scan device. US Patent Application Publication US 201701 19658A1, 4 May 2017

Unique Identification Authority of India, Government of India 2016. https:/uidai. gov.in/. Accessed 20 May 2020.

Vatsa M, Singh R, Bharadwaj S, Bhatt H, Mashruwala R (2010) Analyzing fingerprints of Indian population using image quality: a UIDAI case study. In: International Workshop on Emerging Techniques and Challenges for HandBased Biometrics, pp 1-5. https://doi.org/10.1109/ETCHB.2010.5559279

Wayase S, Chaulang G (2018) Review of dactylography interfacing with computers. Int J Sci Res Comput Sci Eng Info Tech 3(1):750-754

What is mehendi? (2002). https://ssbea.mercer.edu/patelr/mehndi.htm. Accessed 2 June 2020.

Win KN, Li K, Chena J, Viger PF, Li K (2020) Fingerprint classification and identification algorithms for criminal investigation: a survey. Future Gen Comp Sys 110:758-771. https://doi.org/10.1016/j.future.2019.10.019

\section{Publisher's Note}

Springer Nature remains neutral with regard to jurisdictional claims in published maps and institutional affiliations.

\section{Submit your manuscript to a SpringerOpen ${ }^{\circ}$ journal and benefit from:}

- Convenient online submission

- Rigorous peer review

- Open access: articles freely available online

High visibility within the field

- Retaining the copyright to your article

Submit your next manuscript at $\boldsymbol{\nabla}$ springeropen.com 